Instructions for authors, subscriptions and further details:

http://ijelm.hipatiapress.com

\title{
University organizational culture through insider eyes: A case study of a writing program
}

Haley Orton ${ }^{1}$, Sharon Conley ${ }^{1}$

1) University of California Santa Barbara. USA

Date of publication: January $16^{\text {th }}, 2016$

Edition period: January 2016-July 2016

To cite this article: Orton, H., and Conley, S. (2016). University organizational culture through insider eyes: A case study of a writing program. International Journal of Educational Leadership and Management, 4(1), 48-71. doi: 10.17583/ijelm.2016.1687

To link this article: http://dx.doi.org/10.17583/ijelm.2016.1687

PLEASE SCROLL DOWN FOR ARTICLE

The terms and conditions of use are related to the Open Journal System and to Creative Commons Attribution License (CC-BY). 


\section{University Organizational Culture through Insider Eyes: A Case Study of a Writing Program}

Haley Orton

University of California Santa

Barbara
Sharon Conley

University of California Santa

Barbara

\section{Abstract}

Using a case study approach, the authors examined university administrator and instructor perspectives about a writing program's organizational culture. In so doing, members of the writing program were invited to participate in interviews over a three-year period. This qualitative case study suggests that examples of culture through a three-lens perspective (integration, differentiation, and fragmentation) provided a more nuanced reading of the program's identity than a single lens could. The authors suggest that this multi-frame view of organizational culture for understanding policy and practice has implications for academic program leadership.

Keywords: organizational culture, academic programs, higher education, writing instruction 


\section{La Cultura Organizacional Universitaria Vista desde Dentro: Un Estudio de Caso de un Programa de Escritura}

Haley Orton

University of California Santa

Barbara
Sharon Conley

University of California Santa

Barbara

\section{Resumen}

Utilizando un enfoque de estudio de caso, las autoras examinan las perspectivas del administrador universitario y del profesor sobre la cultura organizacional de un programa de escritura. Se invitó a los miembros del programa a participar en entrevistas durante un periodo de tres años. Este estudio de caso cualitativo sugiere que enfocando la cultura a través de una perspectiva de trifocal (integración, diferenciación y fragmentación) proporciona una lectura más matizada de la identidad del programa que si se hiciera desde un solo punto de vista. Las autoras sugieren que este punto de vista múltiple de la cultura organizativa para la comprensión de la política y la práctica tiene implicaciones para el liderazgo del programa académico.

Palabras clave: cultura organizativa, programas académicos, educación superior, escritura 


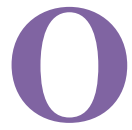

rganizational culture has been defined as "the ways in which people know and understand the values and beliefs of a specific group of people or an institution" (Taplay, Jack, Baxter, Eva et al., 2014, p. 1). Similarly, what Bush (2011) termed cultural models of leadership and management "assume that beliefs, values and ideology are at the heart of organizations" (p. 170). Schein (2010) defined organizational culture as a "pattern of shared basic assumptions learned by a group" (p. 18), which occurs on three different levels. The first, that of artifacts, is the most visible level of culture and includes physical manifestations such as building design as well as climate or member behavior. Espoused beliefs and values comprise the second level, with the third and deepest level occurring "when a solution to a problem works repeatedly [and] comes to be taken for granted" (p. 27). According to Schein, the most fruitful examination of culture occurs at its deepest levels (see Taplay et al., 2014).

Different from Schein (2010), conceptions of organizational culture were also proposed by Meyerson and Martin (1987), Martin (1992) and later, Enomoto (1994). According to these authors, many prominent perspectives on culture focus on the ability and inherent nature of culture to bring unity to an organization. When the primary focus is on unity, the researcher may overlook the complexities within the organization that make it unique, affect the way it functions (either positively or negatively), and/or affect how the organization responds to change and flux. Thus, frameworks of organizational culture are needed that propose different vantage points from which to examine how organizational members interact with each other, providing a wider frame for understanding policy and practice (Enomoto, 1994). This case study provided an opportunity to explore such questions.

In this context, U.S. writing programs charged with teaching writing to undergraduate students display many attributes of complex, if not somewhat fragmented, cultures. According to Russell (1987) and McLeod (2007), writing programs struggle between being a "service" program, meeting requirements to teach students writing, and representing a unique academic discipline. This discipline, referred to as writing studies (also termed composition, or composition and rhetoric), has a distinct curriculum and scholarly foundation. Additional complexities include a growing national 
interest in many U.S. colleges and universities in separating writing programs from their traditional housing within English departments. This move can be expected to grant such programs increasing independence in their operations (Charlton \& Rose, 2009). Independent writing programs that have been introduced over the last 25 years have experienced high levels of uncertainty and ambiguity, as well as frequent shifts in leadership (Charlton \& Rose, 2009). Zhu and Engels (2014) noted that organizational culture has recently become embedded in research in higher education academic programs. For example, studies have related organizational culture to both "students' and teachers' values and beliefs which affect the teaching and learning process... and a supportive institutional environment [that] can facilitate teachers' innovations and student academic achievement" (p. 138; see also Bush, 2011). However, with some exceptions (Haberkern, 2009; Taplay et al., 2014), not much research has examined academic program participants' perspectives on their organizational culture from multiple viewpoints.

This study originated with a desire to consider the issue of organizational culture within the context of one U.S. university's writing program that had undergone a move from the English department to become an independent writing program in the early 1990s. The authors examined program participants' perceptions of the culture of the program from a view of culture that would consider "the process by which individuals develop their viewpoints, [as] linked to the social fabric of the group as a whole" (Enomoto, 1994, p. 190). This study explored perceived organizational culture from administrators' views of the program they led, as well as instructors who were attempting to adjust to a shift from emphasizing a service ethic in the program to one also focused on writing as its own unique discipline. The authors used the organizational culture framework developed by Meyerson and Martin (1987) and Enomoto (1994), which examined organizational collectivism, while also acknowledging subcultures, organizational flux, and ambiguity in order to address the evolution of new approaches to the writing program.

\section{A Framework for Organizational Culture}


To create a composite picture of organizational culture, Meyerson and Martin (1987) and Enomoto (1994) explicated three views of culture: integration, differentiation, and fragmentation. The integration view emphasizes a unified culture, where individuals in the organization share values and beliefs, and promote formal and informal practices such as "rituals, stories, jargon, humor, and physical arrangements" (Enomoto, 1994, p. 195) that reinforce the whole. Similar to traditional notions of organizational culture, the integration perspective highlights group unity, illustrating how organizational roles, responsibilities, and values are coordinated. The integration perspective further assumes that organizational leaders establish and maintain organizational culture.

At the same time, according to Meyerson and Martin (1987) and Enomoto (1994), there exist subcultures or subdivisions in organizations. In this second view, differentiation "reflects the subdivisions that permeate the organization and magnify the inconsistencies among the subdivisions" (Enomoto, 1994, p. 190). A focus on subcultures within an organization highlights the inconsistencies and conflicts that may occur within the culture, as well as the "presence of ambiguities between the sub-cultural boundaries" (Enomoto, 1994, p. 198). Enomoto's (1994) study of multiple meanings in policy and practice in a midwestern U.S. K-12 multiethnic urban school setting provided an illustration. Although the focus was on the specific area of student truancy, her identification of subgroups (i.e., teachers, administrators, and students) appeared transferable to other studies. In her study, the multiple interpretations of these subgroups had a dominant influence on policy and practice. This was not to say, however, that the subgroups were themselves necessarily cohesive. For example, the subgroup of teachers varied by subject area department as well as extent of affiliation with the teacher union and other affiliations. Further, ambiguity between sub-group boundaries was illustrated by the school's attendance office where there were "ambiguities in switching roles and with overlapping, nested subgroups" (p. 200) within that office.

A third view of organizational culture, fragmentation, highlights how organizations respond to internal and external complexity through mechanisms that may counter organizational consensus or transcend subcultures. According to Martin (2002), 
fragmentation focuses on multiplicities of interpretation that do not coalesce into the collectivity-wide consensus characteristic of an integration view and that do not create the subcultural consensus that is the focus of the differentiation perspective. Instead, there are multiple views of most issues, and those views are constantly in flux. (p. 107)

Within the school membership in Enomoto's (1994) study, there were individuals in all subgroups (e.g., students, teachers, administrators, and staff) who viewed their roles and responsibilities in the school variously from a "fair and just" orientation or from a "caregiving" orientation. With a focus on student truancy, Enomoto (1994) located an underlying tension between these orientations that "seemed to cause much frustration among the members in dealing with each other on issues of truancy" (p. 201). Put another way, the contradiction between a "fair and just" versus "caregiving" institution caused confusion, fear, anxiety, and ambiguity. This ambiguity, according to Martin (1992) was something that "seem[ed] to be unclear, highly complex or paradoxical" (p. 134). The paradoxical views highlighted in the fragmentation lens present a more complex view of organizational culture than do the previous two perspectives. As Enomoto (1994) advised, it was from these three views of organizations as integrated, differentiated, and fragmented that organizational culture may be examined.

\section{Dynamics of U.S. Writing Programs}

Writing programs exist at U.S. universities and colleges in many forms, such as independent or department-specific. As noted above, writing programs' cultures are often characterized by a struggle between "service" requirements and the demands of a traditional academic discipline (McLeod, 2007; Russell, 1987). Many writing programs are located within university English departments and others are dispersed, with faculty from many different academic departments teaching one or two sections of writing in that discipline over the course of a year (Charlton \& Rose, 2009). Independent writing programs or departments--i.e., those with autonomy from English departments--have been gaining in numbers in the U.S. Independent writing programs may be led by a tenured faculty member, an untenured faculty member, or even, in rare cases, an instructor or academic 
counselor (Charlton \& Rose, 2009). English departments may also outsource writing courses to other departments, suggesting further change in the evolution of university writing expectations.

Offering a historical perspective, Russell (1987) and Heckathorn (2004) suggested that for researchers studying writing program organization, of importance was how the various components of writing programs today formed, what influenced their operations, and what struggles they faced. In brief, writing was first a basic general education requirement that was implemented after the American Civil War (McLeod, 2007). Conceptions of writing and what the teaching of writing should entail changed the classroom structure and curriculum of writing courses. At many universities, writing courses were and still are housed within English departments. According to McLeod (2007), English departments desired to maintain control over writing courses because writing was universally required of students, thereby guaranteeing enrollments that would provide a stable source of funding and power within the university. As McLeod (2007) indicated, "Perhaps inevitably, departments became ambitious and competitive for resources; English [departments] began to eye unoccupied territory, including writing, for acquisition" (p. 27). However, for numerous reasons, writing programs and departments have increasingly separated from English departments (McLeod, 2007).

The above literature establishes a need to study writing programs for two reasons. First, writing programs with shifting priorities may experience uncertainties over a given period of time. The writing program under study, since its founding, has undergone structural changes, curricular changes, and leadership changes. Through contextualizing writing programs and conceptualizations of literacy in American writing programs in general, one understands how various changes to the writing program studied here may have yielded different outcomes. Second, scholars in the field of writing have challenged researchers to complicate writing program histories to understand the organizational culture of writing programs (Gold, 2012; McKee \& Porter, 2012). This paper considered these historical aspects as well as how writing programs are emerging now, constructing their own disciplinary identities within their universities.

\section{Case Study}


This qualitative case study research (Merriam, 1997; Stake, 1995) was initiated after recognizing that a writing program that evolved independently from an English department that might on the surface look to have followed a relatively traditional departmental narrative, upon closer examination reveals a complicated culture (Gold, 2012). This study sought to explore whether Meyerson and Martin's (1987) three-lens view of culture (integration, differentiation, fragmentation) might offer some insight into these complexities.

The case study is of the "Writing Program," a program within a large public research institution in the western U.S. The Program serves the university's approximately 19,000 undergraduate students by offering lower and upper division academic and professional (e.g., "business writing") writing courses that fulfilled general education requirements for undergraduates. In addition, as of 1995, the Writing Program offered a minor in professional writing.

Originally housed within the university's English department, the Writing Program petitioned to separate from the department in the early-1990s. According to a program review conducted in 1987, the English department accepted this move because despite large enrollments in writing courses, there was a desire to reduce the department's oversight of instructors. Initially headed by one director, the Writing Program had approximately two administrative staff and 15 instructors, growing to almost 30 instructors by 2006. When the director retired in that same year, an external review characterized the Program as having attained a "culture of support and innovation in which those who work and teach in the program are encouraged to perform at the highest level" (system documentation). Under two new acting co-directors from 2007 to 2011, the Program remained stable in numbers and course offerings but was increasingly challenged with a deteriorating budgetary climate in the western state. During this period, concern emerged about whether the budget allocated to the Program would be adequate. This budgetary concern indicated that the Program would need to take action to ensure its continued presence and viability on campus.

\section{Methods}


In the academic year 2009-10, one of the authors was a participant researcher who advised students in the Writing Program and periodically attended faculty meetings. In spring of 2010 and winter of 2012, interviews were conducted with nine administrators and instructors. In spring of 2013, a second set of interviews was conducted with the new leadership (the second director was appointed in the 2010-11 academic year), two other administrators, and nine additional instructors. Of the original two acting codirectors, one had reverted to a faculty position and the other had become the Program's associate director, a position she held while maintaining teaching responsibilities. In addition to interviews, we examined program documentation, including program reviews and self-studies. Like Enomoto (1994), data analysis proceeded in "an emergent process of sorting, classifying, and categorizing the data collected to describe the organizational culture" (p. 192) by identifying artifacts that connected to social norms and values and beliefs. The case study sought to characterize the purpose and operation of the Program, the members' views of its culture, and strategies proposed by the leadership. We strove to first apply an integration lens; how and why members appeared unified in attending to primary program identities. Next, we considered the differentiation lens focused on subcultures, providing a closer look at the cohesiveness and overlapping roles of subgroups. Finally, we applied the fragmentation lens to the Program to reveal issues that individual members shared and those about which they disagreed (Enomoto, 1994).

\section{Findings}

\section{Integration}

The integration view of the Writing Program attended to three primary program identities (Enomoto, 1994): (1) disciplinary; the Writing Program as a visible and independent entity on campus with a disciplinary orientation; (2) service; the Program as dedicated to students, thereby meeting a service ideal; (3) restructuring; the Program as evolving to meet student needs, implying transparent communications. For example, although service to the campus was stressed by some, the second identity, to serve students (service), was articulated by several instructors. According to one, 
the goal of the Program was to "have students become good writers" and according to another, to enhance students' "solid and in-depth exposure to critical thinking...in written and verbal communication." Another contrasted this focus on students specifically with what could be considered administrators' desires:

[The focus is] certainly on the students and their needs. ...This is a consequence of [the Program's] autonomy and its broad-based approach. We are able to focus on students' needs as opposed to an administrativelyimposed vision of what they [determine] students might appear to need. ...If you look at the curriculum development in this program, it has all come out of a direct read on what students need professionally when they get out of here and what they need here on campus.

An underlying sense of the Writing Program as a collegial organization encompassed the above three program identities. In a collegial organization, a "shared vision" is a basis for collegial decision-making (Brundrett, as cited in Bush, 2011, p. 74). Collegiality was perhaps most visible in the Program's yearly retreats and its several committees comprised of instructors who worked together to "solve a problem" or "get a new project off the ground." The associate director provided an example: "Every year we identify a big effort at our retreat," continuing that "next year's big effort" was "going to be connected to a [writing] assessment." 1 In that effort, "instructors would work collaboratively" with a focus on developing the assessment's range, details, and desired outcomes. Notably, these collaborative examples adhered to two program identities, disciplinary and restructuring; Program participants were working together to establish a visible and cohesive program with a disciplinary identity while also evolving to meet students' needs.

Because the integration perspective typically focuses on "a leader as the primary source of cultural content" (Meyerson \& Martin, 1987, p. 625), it was useful to examine the leadership and its direction. In spring of 2009, when the study began, the Writing Program's leadership at the program level included its direction by the two acting co-directors; by summer 2011, it was headed by the newly appointed director (previously described). During the 2011-13 academic years, the program leadership included several levels: first, the director, who headed the Program; second, the associate director 
(i.e., one of the two former co-directors), whose guidance primarily included curricular restructuring; third, administrative and student services managers who provided administrative support to the Program; and fourth, an undergraduate advisor. The new director was from another university system whose appointment as director (and professor) brought in a new set of priorities for the Writing Program, one that envisioned writing as reimagining the service function and aligning more with writing as a unique discipline (i.e., the first disciplinary identity). Endorsing the scholarly foundations of writing, she established an academic tone to the Program. For example, she participated in academic committees as well as the university academic senate through her appointment as professor, something the previous interim co-directors could not do by virtue of their positions as instructors. By this participation, she modeled the values she desired to see in other Writing Program staff members, such as teaching responsibility and campus involvement. Indeed, the instructors who were interviewed characterized the director as highly "visible" on campus, thus reinforcing the disciplinary orientation.

The Writing Program's hierarchical leadership at the university level also included its direction by a divisional dean within one of the university's colleges who the director sought for approval on "personnel, budget, and curriculum" decisions. Leadership changes can mean top-down transformation of organizational culture throughout the organization (Enomoto, 1994) and several specific changes were made by divisional and program administration. At the university level, this divisional dean implemented staff restructuring throughout the division focusing on reducing the budget and eliminating staff positions. These actions were felt in the Writing Program by the reduction of one administrative staff. At the program level, the director and associate director also initiated changes; largely, a curricular restructuring effort focused on strengthening the professional writing component, in part by expanding the number of professional areas that would be reflected in coursework.

\section{Differentiation}

The differentiation lens provided a closer look at dominant subgroups that also placed different emphases on the three program identities identified above. Foremost, the two subgroups most evident from the interviews 
consisted of administrators and instructors. Instructors provided instruction, and administrators managed and supported the Program. Two administrators who provided direction to the Program, the undergraduate advisor and the director, described the administrator subgroup as collaborative and cohesive. For example, the undergraduate advisor worked closely with the director to negotiate course offerings required for students outside of the Program and in another department. She described her calculations of the numbers of students who were expected to enroll in the courses versus actual numbers; her thoughts on why some students were not properly enrolled; and possible solutions to the problem. She said the director then "took the initiative to explain our side to the other department." According to Taplay et al. (2014), such actions could be considered "scaffolding, ... an element of organizational culture" (p. 9) that involves reaching outside of one's academic program to others to acquire support, thus managing change in ways that benefit more than one program within the same institution. This same advisor further noted that their working relationship was beneficial in making these external relationships and linkages. She stated:

I really like [our relationship] because... either [the director] can rattle things off to me or I can rattle off things to her. ... She's always able to take it and put it in a memo form, and kind of rearrange some stuff to make it more straightforward [and understandable to others].

Although the administrative subgroup was described as cohesive, in line with Enomoto's (1994) observation of overlapping roles among subgroups, such overlap existed between the administrator and instructor subgroups. For example, the director (and, previously, the co-directors) also taught courses within the Program. In addition, some faculty served as leaders of program committees responsible for overseeing such core functions as curriculum. These instances of overlapping roles also reflected activities concerned with discernible identities in the integration view.

While the most prominent subgroups were administrators and instructors, each was not necessarily cohesive as a group. For example, the subculture of instructors was heavily influenced by their teaching assignments, most notably in academic or professional writing. For instance, one interviewee described a divide between instructors, with some "focused on a research discipline, an academic [discipline]," such as "the people who came out of 
the humanities" in their previous graduate-level studies. Others, by contrast, "primarily [focused on] writing for the workplace," such as those coming from professional backgrounds such as the legal field. These divisions were most recently reinforced by a new course numbering system, notably a form of restructuring (the third identity) that would also reinforce the disciplinary identity of the Program. According to one instructor:

Some people feel strongly about where a course that they've been teaching for a long time is placed [in the numbering system]. ...A lot of placement of [courses] determines whether [placement is] more about sort of the academic discipline side of that versus the professional approach.

Thus, the Program appeared to be struggling over its disciplinary identity construction, such as whether courses would count in other departments and along the lines of subgroup divisions, i.e., whether instructors were concerned more with academic or professional writing. Even if a member could not place him or herself in either subdivision, interviewees still mentioned this divide. One instructor, after acknowledging the academic and professional writing subdivision, described herself as trained in the humanities but with more professional writing tendencies. She indicated a willingness to teach courses that she knew she could teach well, whether from the (primarily lower division) academic-based courses to the (primarily upper division) professional writing courses, thus crossing this subdivision.

In addition to academic versus professional writing, another sub-divide was based on pedagogical practices. These practices related to the establishment of the Program's disciplinary identity. One instructor (teaching primarily in academic writing for engineering students) said, "Archetypally, we have, for example, rebels. We have staunch traditionalists. We have quirky subcultures - people who try things or are apt to experiment with their classes." Rebels were those who might attempt alternative types of teaching, instructing from different disciplinary traditions. Another instructor (with an English background, teaching primarily academic writing) might have been identified as a traditionalist. He described his teaching practice as focused mainly on "the sentence, on how a paragraph is put together and the words you're using, ... on writing with style." The instructor whose training was in engineering emphasized experimentation (perhaps within the quirky subculture), conveying an interest in the use of 
"traditional hard copy print, electronic text, insertion of picture or graphics, hyperlinking to other references, [and] video" and incorporating these into his classes.

The faculty group was also subdivided by membership on various committees within the Program. Committee participation within the collegial organization identified earlier was mandatory but instructors could select the committee(s) on which they preferred to serve. These committee subgroups were described as cohesive. One instructor, for instance, stated, "I can speak to certain cases where I've had very strong disagreements with people, but we have not let it bleed into... sitting on a committee. We might disagree, we might have strong feelings, but at the same time, we'll get along." According to another, "When the smaller committees break out [of the larger group] there's more intense conversations [within groups] about how to proceed."

Furthermore, individuals might have been members of one or more overlapping subcultures. This overlap was illustrated during the time the Program was without a permanent director. Interviewees recalled the administrative services manager and some instructors assuming administrative responsibilities, conducting their work with minimal supervision, and/or independently managing daily routines (e.g., one instructor chose to redesign and rewrite program advising materials). As one put it, "Different people took up different tasks." According to the associate director, when she served as instructor as well as co-director (prior to the director's appointment), she also assumed responsibility for implementing the new course numbering system (previously described).

Finally, there was overlap in subdivisions within subcultures (e.g., providing direction versus administrative support). In the administrator subculture headed by the director, the administrative services manager at times performed program responsibilities with minimal supervision. She described assuming quasi-director as well as administrative support roles especially when co-directors were leading the Program. For example, at times she "ended up having to step in and be more of the resource ... probably with more responsibility and autonomy." She added:

People look[ed] to me to know what was going on and how to achieve whatever is we need to get done: to comply with policy [or to] go about any initiative or task that the department needed to do about curriculum, 
budget, education, or instructor training. ... I needed to be that resource, have ideas, know how to comply. [I] needed to encourage others [in the Program] to get better acquainted with what we do, and make sure they know what they're part of.

\section{Fragmentation}

Although the integration and differentiation perspectives emphasized connectedness and collaboration within the Program either as a whole or as part of smaller subcultures (Martin, 1992; 2002), the fragmentation lens emphasized fluctuation within the organization (i.e., the identities previously described). Using the fragmentation perspective it was often difficult to identify consistent subcultures; instead organizational members often acted alone and leadership was not seen as a driving force. Martin (2002) offered a "light bulb" analogy, whereby each organizational member would be given a light bulb and instructed to switch it on/off when a new policy or practice was proposed or implemented that did (or did not) apply to them. The effect would be that on a given issue, for some members, their bulb would illuminate whereas for others the bulb would remain off. She explained, "From a distance, patterns of light would appear and disappear in constant flux, with no pattern repeated twice" (p. 94).

Several faculty indicated how easy it was for them to perform their particular job in isolation. One stated that the Writing Program was "supportive [and] collegial" -- reinforcing the underlying view of the Program as a collegial organization -- yet "you can spend, if you want to, which maybe is a good thing, all of your time in your own little bubble." She also mentioned that she might feel this way because for much of her time there the Program was without a permanent director and her office was physically separated from others. She noted, "Because we didn't have a leader for so long, I didn't have a baseline [for knowing organizational issues]. I didn't know what anybody [else] thought [about them either]." As to her physical separation, she stated, "The less I know about the political things [the better, because] I can influence [them] very little."

Further, formal acculturation and socialization of new instructors to the Writing Program was noted by some as absent in the years the Program was led by acting co-directors. Interviewees indicated that a new faculty orientation, for example, coincided with the arrival of the new director. Two 
fairly recent arrivals to the Program expressed some confusion about their own roles, however, in contrast with a view of the Program that emphasized integration. Further, when asked about subgroups, neither was able to identify one that they were associated with most directly. One said that she was not involved in any subgroups that might produce "conflicts" or tensions. She added that she often did not know enough about the Program to know which position to take on issues. Echoing this perspective, the other said that she had spent her first year "just kind of going through the motions, ... trying to figure things out and not wanting to step on any toes." She referred to a lack of clarity about the expected balance among teaching, research, and service activities, expressing concern with not "knowing how much research I have to do." She added, "I've heard different things from different people." Following her second year, she described a readiness to take a stronger role, a stance that might clarify these responsibilities.

The integration lens of organizational culture revealed that participants viewed the Writing Program as focused on creating a cohesive disciplinary identity. This identity was primarily based on creating "better student writers" campus-wide, at a variety of levels and across a variety of disciplines. Program administrative staff and instructors also reported a nuanced reading of this identity. Several expressed that the Program provided a university service, whereas others identified their focus as less on university service and more on service to students (the second identity), in teaching them a unique discipline that could carry over to their other courses (in other departments). The director recognized that some instructors viewed writing as a service to the university and that she would not be able to eliminate this perspective entirely. She appeared to address this complexity when she said, "I just hope that if people see [teaching writing] as a service they don't go to colleagues [in another department] and say...our job is just to serve you." As noted, this view of writing as a "service" field was tied to its historical roots when writing and composition courses were perceived as providing a service to the other programs on university campuses. This view of writing as service versus discipline was constantly in flux.

Another example of multiple and at times paradoxical views was in the area of personnel evaluation. Although transparency and organizational communication emerged as a primary program identity (i.e., the third restructuring identity and the cross-cutting identity of the Program as collegial), when asked about ambiguity, the instructors indicated a tension 
between perceiving the evaluation process as transparent and friendly (often on the part of senior instructors) versus uncertain at best. This tension created some anxiety in the personnel review process. One senior instructor characterized the process as largely collegial, but acknowledged that it had created tension. She indicated her dismay "when people say, well, the [evaluators] are against us and all that kind of stuff. If they only sat in on the meetings they would know that's not true." Another experienced instructor said:

I think that there is a lack of comfort with evaluating others. . . because we don't really know what we expect. ... Our requirements are staggering, in terms of what has to go in the [evaluation] portfolio. ${ }^{2} \ldots$ I think that's because people don't know what [evaluators] want to know. ... Or, they don't trust that [evaluators] can identify some markers of what [constitutes] evidence of high-quality instruction and [instructors'] professional development.

This instructor went on to say that excessive time was spent "talking about reviewing people [when] we should be spending time together, not just reviewing each other." The unease created between "collegiality and support" versus "evaluation" was buttressed by uncertainty about specific requirements (e.g., requirements for research).

Challenges to the Program also included a lack of consensus about ways to address larger campus issues. Just as many instructors were experimenting with pedagogy through newer technologies, the larger university system had begun to experiment with online education. This initiative had already become fraught with tension within the Program and the director noted the complexity of the issue. During a faculty meeting one attendee observed, a discussion about the Program's involvement in the initiative was dynamic and certainly not unified. Some faculty expressed concerns about online education as well as potential benefits of being involved in the initiative. No clear divisions formed during the meeting and the director did not ask members to publicly choose a side. The meeting acted as an introduction to the developing issue. This example illustrated a fragility to the first identity of the Program as an independent entity with a disciplinary orientation; it had not established enough of a view of this identity in this instance to 
coalesce on it, and thus there is a breakdown in organizational culture on this issue. $^{3}$

\section{Discussion and Implications}

This paper suggests the value of "three lenses together" (Enomoto, 1994, p. 203) to analyze organizational culture that affords "alternative points of views that members and researchers bring to their experience of culture" (Meyerson \& Martin, 1987, p. 624). The integration view encourages researchers to use "'shared' as a codebreaker for identifying relevant manifestations of a culture, seeking, for example, a common language, shared values, or an agreed-upon set of appropriate behaviors" (Meyerson \& Martin, 1987, p. 624). In this study, an underlying sense of the Program as collegial was voiced by many participants, and encompassed the three program identities. The identification of program identities are important in this context, as over time they become part of the "way we do things around here" (Deal \& Kennedy, 1982, p. 4). The integration view, however, downplays ambiguity, recognizing "only those cultural manifestations that are consistent with each other and only those interpretations and values that are shared ... that which is clear" (Meyerson \& Martin, 1987, p. 625).

The differentiation perspective, by contrast, views culture as composed of a collection of values and manifestations, some of which may be contradictory: "Subcultural differences may represent disagreements within an organization's dominant culture as in a counter-culture ... or a subculture might enhance a dominant culture" (Meyerson \& Martin, 1987, p. 630). An example of the former was seen in this study when an instructor used the example of rebels and quirky subcultures (those experimenting with the teaching of writing), which constituted a contrast to the integration view of culture as a unified whole. As Bush (2011) added, "There may be several sub-cultures based on the professional and personal interests of different groups" (p. 175).

Within the fragmentation view of culture, "cultural manifestations are not clearly consistent or inconsistent with each other" (Meyerson \& Martin, 1987, p. 637). In this study, having identified three identities, some participants indicated that they spent time in their own "bubble" rather than in a unified Program. In addition, occasional statements about role 
"confusion" indicated that the work done to create a cohesive disciplinary identity (the first identity) was not being recognized by some. Furthermore, from a fragmentation view, there were examples of how participants perceived identity differently; to some, identity was less about service to the campus and more about establishing a unique discipline of writing that students could carry over to courses in other departments. The three-lens view of culture thus provided a more complex picture of the culture of the Program than one alone could.

The three-lens view of organizational culture examined here suggests some implications for academic program leadership. First, leadership might strive to encompass more nuanced readings of program identity where divisions occur (e.g., service to a university versus service to students). Although this case study was of a single program, the perspective offered here might spark thinking about how leaders can express program identities that are more nuanced and capture a wider set of participants' understandings about organizational culture.

Second, leaders might attend to the acculturation or socialization of new members, a problem for all human organizations (Redman et al., 2015). Knowledge transferred to new members reveals what the institution values (Taplay et al., 2014). As Taplay et al. (2014), drawing on Schein (1985), noted, "The culture of the organization is taught to new members so that they can learn how to think, feel and act in relation to the work environment" (p. 11). In this study, acculturation and socialization to help newcomers adjust appeared absent in the years the Program was without a director. Some recent entrants indicated that they did not know enough about the Program to ascertain which position to take on issues under discussion. As one instructor said, she spent her first year "just kind of going through the motions ... trying to figure things out and not wanting to step on any toes." Recommendations might be to include mission, vision, and norms in the orientation of new members to facilitate "shared norms and meanings" (Bush, 2011, p. 186), without an overly prescriptive approach (Redman et al., 2015). These elements would provide an opportunity to show the value of a cohesive departmental identity within this independent program as part of the culture. ${ }^{4}$

Third, leaders might alter aspects of personnel evaluation in ways that take into consideration the disconnect revealed in the fragmentation lens between the cross-cutting program identity of collaboration on the one hand 
and the often unidirectional communications characteristic of personnel evaluation on the other (e.g., "we should be spending time together, not just reviewing each other"). What provides better long-term benefits: the traditional unidirectional approach or the collaborative approach, and in what areas? A sense of ambiguity existed about personnel evaluation (e.g., how evaluators would count work performed on committees versus on other requirements such as research). As Taplay et al. (2014) suggested, it is an expectation in most universities that some form of annual performance evaluation is performed. Taplay et al.'s (2014) interviews with faculty members of nursing programs in Canada to examine organizational culture reported that the work faculty had conducted in relation to an innovation (a teaching simulation) was not well reflected in the performance evaluation process. The authors suggested that such a "disconnection provides an ideal opportunity for leaders to communicate, share information and align work contributions so they fit within the parameters of the appraisal process" (p. 11).

Similarly, in this study, despite the value placed on delivering highquality instruction to students, participants shared that personnel evaluation had created tension with reduced trust by some in evaluators. One questioned trusting evaluators to "identify some markers of what constitutes evidence of high-quality instruction and [instructors'] professional development." This participant's view suggested a sense that the work being done to achieve high-quality teaching may not have been fully recognized in personnel evaluation. In writing about organizational learning, Collinson, Cook, and Conley (2001; see also Collinson \& Cook, 2007) indicated that any organizational change, such as restructuring (the third identity), might mean that entire systems, including university systems of personnel evaluation, would require re-examination. As these authors pointed out metaphorically, if one pulls a single thread out of a tapestry other threads can also be affected by that single thread. Should the work being accomplished on high-quality instruction not be fully recognized in personnel evaluation, this might indicate a need for greater interconnectedness in elements of organizational culture. As Taplay et al. (2014) suggested, dimensions of organizational culture are often presented in isolation from each other, when programs should "look at these aspects from a holistic viewpoint, knowing that one element of organizational culture impacts the other" (p. 11). Further, in line with Martin (2002), 
organizational researchers should take the three perspectives, integration, differentiation, and fragmentation, into account "not sequentially but simultaneously" (p. 120). As she stated, "Each perspective has conceptual blind spots that the combination of the three does not" (p. 120).

A third and related implication for leadership is the encouragement of experimentation with teaching (Zhu \& Engels, 2014). Participants in this study shared that restructuring to meet student needs was a primary program identity, yet one instructor termed some program participants who experimented with their teaching rebels. In another instance, an interviewee's teaching style was characterized as traditional. The rebel perspective suggested that experimentation with teaching might have been viewed as outside the norm. However, the Program's continued motivation to establish a norm and culture that incorporated rebel views spoke to its effort to create an inclusive program that addressed teaching across disciplinary fields as well as students' needs across campus. Little (1984) noted that leaders have an important role to play to create an enhanced culture of experimentation with teaching. Put another way, attending to what rebels and quirky subcultures are trying to do to innovate could provide fertile examples to which leaders could attend. This research demonstrated the difficulty of achieving this focus, particularly within an emerging program still seeking to solidify its identity.

Finally, with regard to limitations, the data itself might not have been adequately comprehensive in scope. Data collection was confined to administrators and instructors and students were not interviewed. This limitation may explain why there was a tendency for our data to primarily illustrate the first and third program identities (disciplinary and restructuring), as opposed to the second, service to students. This limitation may have owed to the students' views being a missing component of the program identity in this study. In addition, this study involved an established academic program on a single campus. Studies utilizing multiple campus settings (Taplay et al., 2014) and/or newer departments may have yielded different results.

\section{Notes}


1 Writing assessment, or the evaluation or scoring of writing, is important to writing instruction because "learning to write better involves engaging in the process of drafting, reading, and revising; in dialogue, reflections, and formative feedback with peers and teachers; and in formal instruction and imitative activities" (National Council of Teachers of English and the Council of Writing Program Administrators, n.d.).

2 Portfolios refer to the required faculty evaluations that detail the teaching, service, and research instructors complete during a given period of time and submit as part of the evaluation process.

${ }^{3}$ Writing program members were specifically grappling with the idea of participating in online instruction due to administrative mandate as opposed to participating based on their own assessments of the derived benefits of such instruction to the Program. Participants varied in their views on this struggle.

${ }^{4}$ Inclusion of peer mentoring in the orientation, where an instructor teaching the same course or type of course would mentor a new instructor, might similarly show the value of collegiality through sharing of resources and the learning of expectations. 


\section{References}

Bush, T. (2011). Theories of educational leadership and management, 4th edition. London: Sage.

Charlton, J., \& Rose, S.K. (2009). Twenty more years in the WPA's progress. Writing Program Administration, 33(1-2), 114-145.

Collinson, V., \& Cook, T. F. (2007). Organizational learning: Improving learning, teaching, and leading in school systems. Thousand Oaks, CA: Sage.

Collinson, V., Cook, T. F., \& Conley, S. (2001, August). Organizational learning: Theory and applications for schools and school systems. Paper presented at the Annual Conference of the Association for Teacher Education in Europe, Stockholm, Sweden.

Deal, T. E., \& Kennedy, A. A. (1982). Corporate cultures: The rites and rituals of corporate life. Reading, MA: Addison-Wesley.

Enomoto, E. K. (1994). The meaning of truancy: Organizational culture as multicultures. Urban Review, 26(3), 187-207. doi: 10.1007/BF02354958

Gold, D. (2012). Remapping revisionist historiography. College Composition and Communication, 64(1), 15-34.

Haberkern, A. (2009). The culture of study abroad in the 21 st century. A case study of organizational response to growth. Unpublished doctoral dissertation, Proquest Digital Dissertations, 3390749.

Heckathorn, A. (2004). Moving toward a group identity: WPA professionalization from the 1940s to the 1970s. In B. L'Eplattenier \& L. Mastrangelo (Eds.), Historical studies of writing program administration: Individuals, communities, and the formation of a discipline (pp. 191-220). West Lafayette, IN: Parlor Press.

Little, J. W. (1984). Norms of collegiality and experimentation: Workplace conditions of school success. American Educational Research Journal, 19(3), 325-340. doi: 10.3102/00028312019003325

Martin, J. (1992). Cultures in organizations: Three perspectives. New York, NY: Oxford University Press.

Martin, J. (2002). Organizational culture: Mapping the terrain. Thousand Oaks, CA: Sage Publications. doi: 10.4135/9781483328478 
McKee, H. A. \& Porter, J. E. (2012). The ethics of archival research. College Composition and Communication, 64(1), 59-81.

McLeod, S. H. (2007). Writing program administration. West Lafayette, IN: Parlor Press.

Merriam, S. B. (1997). Qualitative research and case study applications in education: Revised and expanded from case study research in education. San Francisco: Jossey-Bass.

Meyerson, D., \& Martin, J. (1987). Cultural change: An integration of three different views. Journal of Management Studies, 24(6), 623-647. doi: 10.1111/j.1467-6486.1987.tb00466.x

National Council of Teachers of English and the Council of Writing Program Administrators (n.d.). White paper on writing assessment in colleges and universities. Retrieved from: http://wpacouncil.org/whitepaper.

Redman, D., Conley, S., \& Deal, T. E. (2015). A cultural approach to mentoring new teachers. In B. S. Cooper \& C. R. McCray (Eds.), Mentoring for school quality: How educators can be more professional and effective (pp. 65-80). Lanham, MD: Rowman \& Littlefield.

Russell, D. R. (1987). Writing across the curriculum and the communications movement: Some lessons from the past. College Composition and Communication, 38(2), 184-194. doi: $10.2307 / 357718$

Schein, E. H. (1985). Organizational culture and leadership. San Francisco: Jossey Bass.

Schein, E. H. (2010). Organizational culture and leadership (4 ${ }^{\text {th }}$ ed.). San Francisco: Jossey Bass.

Stake, R. E. (1995). The art of case study research. Thousand Oaks, CA: Sage.

Taplay, K., Jack, S. M., Baxter, P., Eva, K., \& Martin, L. (2014). Organizational culture shapes the adoption and incorporation of simulation into nursing curricula: A grounded theory study. Nursing Research and Practice. Retrieved from doi: 10.1155/2014/197591

Zhu, C., \& Engels, N. (2014). Organizational culture and instructional innovations in higher education: Perceptions and reactions of teachers and students. Educational Management Administration \& Leadership, 42(1), 136-158. doi: 10.1177/1741143213499253 
72 Orton, H. \& Conley, S. - University Organizational Culture

Haley Orton is Academic Advisor at University of Caifornia Santa Barabara.

Contact Address: orton@engineering.ucsb.edu

Sharon Conley is Professor at University of California Santa Barbara.

Contact Address: sconley@education.ucsb.edu 